\title{
The association between shame and substance use in young people: a Systematic Review
}

Masuma Rahim, Robert Patton

BACKGROUND: Shame has been associated with a range of maladaptive behaviours, including substance use. Young people may be particularly vulnerable to heightened shame sensitivity, and substance use is a significant problem amongst UK adolescents. Although there appears to be a relationship between shame and substance use, the direction of the relationship remains unclear. AlM: The purpose of this study was to undertake a Systematic Review of the literature relating to shame and substance use in young people. METHOD: Five electronic databases were searched for articles containing terms related to 'adolescence', 'shame' and 'substance use'. Six articles were included in the final analyses. RESULTS: Adverse early experiences, particularly sexual abuse, predict shame-proneness, and substance use is a mechanism by which some individuals cope with negative feelings. In general, there is a dearth of literature investigating the shamesubstance use relationship in adolescent samples. The available literature associates shame-proneness with poorer functioning and suggests that it may potentially lead to psychopathology and early-onset substance use. Scant attention has been paid to the cognitive and emotional processes implicated. Further research is required to ascertain the strength of the shame-substance use relationship in young people and to develop appropriate interventions for this population. 
Masuma Rahim

University of Surrey

4

Dr Robert Patton

5

University of Surrey 
Introduction

7 A significant body of research has investigated the effect of factors related to self8 concept on substance use in young people. Self-esteem, impulsivity and shame have 9 all been associated with alcohol and other drug use in young people but existing understanding of the association with shame in particular is limited. This paper will review current empirical and conceptual understanding of the association between shame and substance use in this population. It is of note that drug and alcohol use ranges from 'experimental' to 'harmful' and that some young people report 'nonproblematic' or 'recreational' use (Bauman \& Phongsavan, 1999; Martin, Chung, \& Langenbucher, 2008). The papers reviewed here use a variety of terms to describe use of alcohol and other drugs; consequently, the term 'substance use' refers to all levels of use throughout this paper.

Shame relates to global, negative feelings about the self (Dearing, Stuewig, \& Tangney, 2005) and has been described as an intense negative emotion which can result in feelings of inferiority and powerlessness (Wicker, Payne, \& Morgan, 1983). Shame can arise from a disparity between the ideal self and the actual real self, leading to feelings of inadequacy and disgust. Although it

23 is generally associated with negative consequences, it is notable that shame is universally experienced and that moderate levels can be beneficial in enabling individuals to evaluate themselves and their actions and to moderate them appropriately (Cook, 1987; Nathanson, 1987; Potter-Efron, 1987). Much of the literature has sought to distinguish the concepts shame and guilt, although, historically, it has failed to do so adequately (Kugler \& Jones, 1992). More recently, it has been suggested that both emotions are essential to the experience of being human and that they can occur either independently or in tandem with each other (Clark, 2012). Both shame and guilt enable self-evaluation and serve to guide our interactions with others (Tangney \& Dearing, 2002). Shame has been described as a 'failure of being', or global self-condemnation, whilst guilt has been referred to as a 'failure of doing' (Potter-Efron, 1987). The former may result in feelings of inadequacy, deficiency and being 'exposed'; the latter is associated with an individual feeling 'wicked' and remorseful. Whilst vulnerability to 
38 guilt may result from conflict between the actual self and the 'should' self (Moretti \&

39 Tory-Higgins, 1990). It appears that shame is directed primarily at the self, whereas

40 guilt addresses the particular act, and may be implicated in conformity to societal

41 norms (Quiles, Kinnunen, \& Bybee, 2002). Shame-proneness is often internalized

42 and has been associated with the development of psychopathology, whilst

43 proneness to guilt, generally more overt, correlates with non-pathological, adaptive

44 empathy (Tangney, Wagner, \& Gramzow, 1992). However, far from being a purely

45 negative emotional state, feeling shameful warns the individual that their actions

46 are socially unacceptable and may result in them being rejected by others. In order

47 to avoid rejection, the individual seeks to find alternative ways of behaving

48 (Nathanson, 1987). As such, shame is characterised by 'hiding' the self, whereas

49 guilt may manifest itself in reparative behaviours. Consequently, similar situations

50 can result in distinct responses, depending on the individual's attributional style

51 (Lewis, 2008).

\section{The development of shame in children and young people}

53 The development of shame is dependent on individual possessing sufficient cognitive capacity, having an awareness of social rules and expectations, and an understanding of their behaviour in comparison to those expectations, as well as adequate theory of mind (Gilbert, 2002; Lewis, 2003). As such, it is unlikely that shame develops before the age of two years (Zahn-Waxler, Radke-Yarrow, Wagner, \& 58 Chapman, 1992).

Sexual abuse, insecure attachment styles and harsh parenting have all been associated with the development of shame in children (Feiring, Deblinger, HochEspada, \& Haworth, 2002; Gross \& Hansen, 2000; Jeffrey \& Jeffrey, 1991; Stuewig \& McCloskey, 2005). Shame may develop as a secondary consequence of early adversity; In families where factors such as parental substance use are implicated, children may develop more empathic attitudes as they try to minimise parental disturbance (Lewis, 1995). If they fail to do so, they are likely to blame themselves, developing a negative global attributional style and heightened proneness to shame (Lewis, 1995). Differences in the ways males and females are socialized can result in females developing a greater sense of responsibility and becoming more shameprone than their male peers, despite experiencing similar early life events (Lewis, 1995; Tangney, 1990). 
71 Shame is likely to manifest itself according to the child's developmental stage.

72 Young children may experience shame as feelings of embarrassment and inferiority;

73 coping with this negative affect by behaving in a controlling, critical or rageful 74 manner (Bradshaw, 2005). They may also polarise themselves and others as being 75 'all good' or 'all bad'. During puberty shame can be experienced as limiting one's 76 ability to form their identity and may serve to isolate the individual (Bradshaw, 77 2005). Self-evaluation is central to the development of shame in both younger 78 children and adolescents (Lewis, 1995; Lewis, 2003; Reimer, 1996). Adolescence is 79 conceptually characterised by the development of identity and by separation from 80 caregivers (Koepke \& Denissen, 2012) and It is often here that young people begin 81 to develop meaningful peer relationships (Allen \& Land, 1999). As their capacity for 82 self-reflection and social perspective-taking develops, adolescents are more likely to 83 compare themselves negatively to peers, (Reimer, 1996). Some young people may 84 develop an enhanced vulnerability to feeling shameful, potentially resulting in the 85 use of maladaptive coping strategies such as substance use and making them more 86 vulnerable to depression, eating disorders and suicide (Reimer, 1996). There is some 87 evidence that alcohol use demonstrates a stronger association with 88 psychopathology than other drugs, such as marijuana (Dearing et al., 2005).

\section{Substance use amongst adolescents}

90 In the UK, $84 \%$ of $12-17$ year-olds have drunk alcohol. Over a third are frequent 91 drinkers and $15 \%$ have been involved in antisocial behaviour as a result of drinking 92 (Institute for Alcohol Studies, 2013). The same report stated that two major reasons 93 given for underage drinking were 'escapism' and 'gaining respect from peers'. With 94 reference to illicit substances, $18 \%$ of $11-15$ year-olds report having used drugs; $9512 \%$ having done so in the past year. Cannabis is the most widely-used controlled 96 drug, taken by $8 \%$ of $11-15$ year-olds in 2010. Truanting and school suspension are 97 highly correlated with regular drug use (NHSIC, 2011), and those who begin using 98 alcohol between the ages of 14 and 16 are four times as likely to develop alcohol99 related problems in later life than those who begin drinking in their 20s (Gunzerath, 100 Hewitt, Li, \& Warren, 2011). Despite this, outcomes following intervention remain 101 variable: although 23000 Britons under the age of 18 accessed support for 102 substance use in 2009/10, only one in three completed treatment (NHSIC, 2011). 103 Given that the primary motivators underlying substance use relate to coping with 
104 negative affect, it may be the case that interventions need to more effectively target 105 these factors.

\section{The relationship between shame and substance use}

107 In adults shame has been strongly implicated in behaviours which enable individuals 108 to escape feelings of worthlessness and failure, such as binge-eating, sexual risk109 taking and substance use (Adams \& Robinson, 2001; Hayaki, Friedman, \& Brownell, 110 2002; Peñas-Lledó, Fernández, \& Waller, 2004; Talbot, Talbot, \& Tu, 2004).

111 Heightened shame significantly increases vulnerability to addictive behaviours, 112 particularly substance use (Cook, 1987). Although several studies indicate that 113 shame which arise from the stigma surrounding substance use may serve as a 114 barrier to treatment (Cook, 1987; Corrigan, Watson, \& Miller, 2006; Luoma et al., 115 2007), it has been suggested that this stigma is more pronounced amongst certain 116 groups. In particular, females seeking treatment for substance use and related 117 problems may face greater stigma than males, often risking the breakdown of 118 intimate relationships, as well as the removal of their children (Blume, 1990; 119 O'Connor, Berry, Inaba, \& Weiss, 1994; Reed, 1987). Consequently, females who 120 enter treatment programs often experience enhanced shame and guilt compared to 121 their male counterparts (Mason, 1991).

\section{Rationale for the current review}

123 As described, there is some evidence that shame arises from early adversity and 124 that it is correlated with a range of maladaptive behaviours, including substance 125 use. Substance use is a significant problem amongst young people but little research 126 has investigated the impact of shame on alcohol and illicit drug use in this 127 population. This paper presents a systematic review of the existing evidence 128 investigating the relationship between shame and substance use in young people in 129 order to identify the areas that substance use interventions might focus on in this 130 population.

\section{Search strategy}

132 Five electronic databases were searched (PsycArticles, Psyclnfo, Medline, Web of 133 Science and PubMed) for English-language articles published in peer-reviewed 134 journals for all periods up to, and including, January 2012. Articles were searched for 
135 using terms related to 'adolescence' (e.g., 'adolescen*', 'teen*', 'child*', 'juvenile*',

136 'youth*'), 'shame' (e.g. 'shame*') and 'substance use' (e.g., 'substanc*', 'drug*',

137 'alcohol*', 'illicit*', 'drink'). The use of '*' denotes truncated search terms in order

138 to increase the number of records retrieved. For the purposes of this review,

139 'adolescent' refers to individuals aged 11-19. Where databases could be searched

140 by topic, 'psychology' was specified. After the removal of duplicate records, the

141 search yielded 220 results. Following review of the abstracts, articles were excluded

142 if they were unavailable in English $(n=9)$ or if they focused on unrelated physical or

143 psychological health problems $(n=122)$. Of the remaining 89 articles, 61 were

144 excluded as they did not contribute to the literature relating to the relationship

145 between shame and substance use (e.g. 19 papers focused on shame arising from

146 parental substance use). The remaining articles $(n=28)$ were read to ensure that

147 they included a research question and outcome measures. Seven papers exclusively

148 reviewed the literature, but were not empirical studies. Another five discussed cases

149 and process issues in therapy but did not relate specifically to shame as either a

150 contributing factor or a consequence of substance use. Given that these papers did

151 not contribute to the scientific understanding of the relationship between shame and

152 substance use, they were excluded. A further ten papers were excluded as they

153 used samples of children (pre-teen) or adults (post-adolescent). The final analyses

154 included six empirical papers.

\section{Results}

156 Details of the articles reviewed can be seen in Table 1. All of the papers had been 157 published between 1989 and 2012. Four of the studies were quantitative in 158 methodology; two used a qualitative design. Amongst the quantitative studies, 159 sample sizes ranged from 97-816. The qualitative studies employed 12 and 597 160 participants, respectively. One paper considered the development of shame in young 161 people in treatment for substance use; five investigated the relationship between 162 shame and substance use. 


\section{The role of sexual abuse in the development of shame}

165 Of the six studies reviewed, one investigated factors resulting in heightened shame

166 in later life (Edwall, Hoffmann, \& Harrison, 1989), identifying sexual abuse, including 167 incest, as a predictor of shame-proneness. In their qualitative study of 597 168 adolescent girls, it was found that $35 \%$ of inpatients receiving treatment for 169 substance use reported previous sexual abuse. Sexual abuse was highly correlated 170 with both a history of physical abuse and with having attempted in the previous 171 year. Sexual abuse was also strongly associated with feelings of shame, particularly

172 amongst those who had experienced only extra familial abuse $(p<0.001)$. The 173 authors concluded that adolescent girls with a history of abuse may internalize 174 adverse experiences and construct an image of themselves as 'bad', making them 175 vulnerable to suicidal ideation and the development of mental health problems. 176 However, the categorisation of those who had or had not been abused was 177 problematic; 58 girls who denied having been sexually abused during interviews 178 with the researchers were classified by their therapists as having reported sexual 179 abuse in therapy sessions, and excluded from analyses. Additionally, the researchers 180 made no use of standardised measures, and thus the severity of the shame 181 experienced cannot be assessed. No attempt was made to ascertain the duration or 182 nature of the sexual abuse and only limited information pertaining to the course of 183 the participants' use of substances was available.

\section{The relationship between shame and substance use}

185 Two of the studies included in this review found significant associations between 186 shame-related affect and maladaptive behaviours, including substance use 187 (Abramowitz \& Berenbaum, 2007; Dearing et al., 2005). Abramowitz \& Berenbaum's 188 (2007) study found that the desire to enhance positive affect was a strong motivator 189 of alcohol use, and that shame reliably predicted a range of 'impulsive-compulsive' 190 (IC) behaviours, including substance use, sexual activity, playing video games and 191 obsessive-compulsive-type behaviours such as cleaning. Shame was most strongly 192 associated with substance use (correlation $=0.16 ; p<0.05$ ). It is of note, however, 193 that their data were based on retrospective accounts of behaviours the participants 194 had engaged in during the past three months and that, although the associations 195 reported were statistically significant, causality could not be ascertained. In addition, 196 the sample was aged 16-30 and, as the authors note, many impulsive and 197 compulsive behaviours diminish with age. 
198 Carrying out semi-structured interviews with college students, Lashbrook (2000) 199 found that the desire to avoid ridicule, isolation and feelings of inadequacy was key 200 in alcohol use. Despite the participants in this study not using terms such as 'shame' 201 explicitly, the literature suggests that ridicule, isolation and inadequacy are closely 202 linked to constructs of shame-proneness (Cook, 1987; Potter-Efron, 1987; Wicker et 203 al., 1983). It is possible that low self-esteem was implicated in these negative 204 emotions, although this was not investigated within the study. However, findings 205 reported by Dielman, Campanelli, Shope, \& Butchart (1987) provide support for the 206 suggestion that low self-esteem is associated with vulnerability to peer pressure and 207 increased substance use.

208 Dearing et al. (2005) conducted three studies to test the relationships between 209 shame- and guilt-proneness amongst undergraduate students and prisoners, 210 hypothesising that the former would correlate positively with substance use, whilst 211 the opposite would be true for guilt-proneness. Of their undergraduate sample, $7.3 \%$ 212 reported symptoms consistent with problematic alcohol use and $15.4 \%$ indicated 213 symptoms of problematic drug use. Shame was positively correlated with alcohol 214 problems but not with problematic drug use. In contrast, guilt was found to correlate 215 negatively with both drug and alcohol problems; findings which supported those 216 presented by Quiles et al. (2002). The authors concluded that although shame217 proneness showed some association with problematic drug use, stronger effects 218 were observed with alcohol use. The shame-substance use relationship appears 219 consistent in a range of populations. The authors suggested that alcohol and other 220 drugs may be used in order to cope with negative affect such as shame but noted 221 that use of substances may in itself result in additional shame.

222 The majority of the studies included in this review indicate that vulnerability to 223 shame is associated with increased drug and alcohol use in young people. Some 224 research suggests that feelings of shame can arise as a consequence of using 225 substances (Arentzen, 1978; Blume, 1990; Cook, 1987; Corrigan et al., 2006; 226 Fossum \& Mason, 1986; Luoma et al., 2007; O'Connor et al., 1994; Reed, 1987), 227 and, of the papers reviewed here, one suggests that, amongst those who already 228 use substances problematically, shame may have a positive impact by increasing 229 motivation to seek treatment. In their study of 188 16-24 year-olds entering 
230 treatment for moderately-problematic substance use, (Rosenkranz, Henderson,

231 Muller, \& Goodman, 2012) found that those individuals who reported greater shame-

232 proneness were more likely to recognize their substance use as problematic and to

233 seek treatment. Some research suggests that these individuals demonstrate

234 superior treatment outcomes (Williams et al., 2008), but their data were subject to

235 disclosure biases. Similarly, Rosenkranz et al. (2012) used a measure of treatment

236 motivation which conflates proneness to shame with motivation to seek treatment,

237 and which included items (e.g., If I remain in treatment it will probably be because

238 I'll feel very bad about myself if I don't) open to being interpreted as either 'shame' 239 or 'guilt' by participants.

\section{Discussion}

\section{Summary of findings}

242 This paper sought to review the literature relating to shame and substance use in 243 young people. Despite the search strategy specifying 'adolescent', and variations 244 thereof, only five papers used samples which investigated teenagers and young 245 adults. An additional study carried out by Quiles et al. (2002), used a sample aged $246 \leq 27$ but excluded all those aged 22-27 $(n=17)$ from their analyses; thus, the paper 247 was included in this review. Amongst the remainder of the studies participants 248 ranged in age from 7-80. It appears that there is a significant absence of research 249 into the association between shame and substance use amongst young people and 250 this paucity limits the extent to which theoretical or empirical conclusions can be 251 drawn. It appears that early maltreatment and neglect can result in heightened 252 shame-proneness, possibly as a result of adverse experiences being internalized, 253 and that greater maladjustment results from more severe adversity. Although shame 254 arising from maladaptive early experiences has been found to correlate significantly 255 with substance-using behaviours, it can also motivate individuals to seek and 256 engage in treatment. It is concluded from the evidence reviewed that it is shame 257 which is most heavily implicated in these mechanisms, not guilt.

258 The literature suggests that shame-proneness is generally associated with negative 259 outcomes such as poorer functioning, psychopathology and early-onset substance 260 use Adolescents are more likely to compare themselves negatively to peers (Reimer, 261 1996) and those who develop a heightened proneness to shame may be more likely 
262 to utilise coping strategies such as criminal or risk-taking behaviours in an attempt 263 to gain peer acceptance (Adams \& Robinson, 2001; Arnett, 1995; Hayaki et al., 264 2002; Peñas-Lledó et al., 2004; Talbot et al., 2004).

265 Whilst there is some indication that enhanced shame results in a greater number of 266 maladaptive behaviours (Cook, 1987), it is also suggested that shame-proneness 267 affects males and females differently. Based upon the evidence reviewed, it is 268 tentatively speculated that shame in females results in behaviours which harm the 269 self, such as eating disorders, whereas males tend externalise negative self-image 270 and may act in an antisocial manner. It is suggested that, if shame encompasses 271 negative affect and symptoms typically observed in depression, it is to be expected 272 that young people who demonstrate a tendency towards feeling shame would also 273 score poorly on measures of self-worth and self-esteem.

274 The studies included in this review were conducted using a wide range of outcome 275 measures and methodological designs; each of which demonstrated both strengths 276 and limitations. For the most part, researchers made efforts to distinguish between 277 shame and guilt, a key methodological requirement, given the conceptual overlap in 278 these variables. Nevertheless, it is of note that each of the studies reviewed 279 conceptualised shame in distinct ways and investigated different facets of substance 280 use, further limiting the extent to which overarching conclusions can be drawn.

\section{Gaps in the literature}

282 In addition to the dearth of literature focusing exclusively on adolescent populations, 283 the majority of studies have failed to address use of substances in a discrete 284 manner. Although some studies considered alcohol and other drug use separately 285 (Dearing et al., 2005; Quiles, Kinnunen, \& Bybee, 2002), not all did so. It cannot be 286 presumed a priori that all addictive behaviours are a product of the same 287 mechanisms and this requires further investigation.

288 More fundamentally, although there is some evidence of an association between 289 shame and substance use, there has been little focus on the cognitive and 290 emotional processes which mediate this relationship. Shame is associated with 291 substance use, which has a profound impact on both society and the individual; as 292 such, future work should aim to identify salient risk factors and develop effective 
293 treatments. This review has not included studies which aimed to treat substance use 294 per se; although two studies did recruit participants engaged in treatment programs 295 (Edwall et al., 1989; Rosenkranz et al., 2012) and there is some indication that 296 reducing shame is integral to positive treatment outcomes. Some research suggests 297 that particular factors related to shame, specifically 'fragility and lack of control' and 298 'Ioneliness and emptiness', appear to be associated with addiction (Cook, 1987), and 299 future work should investigate the specific antecedents and maintenance processes 300 of these factors and the implications for substance use treatments. At present, some 301 evidence suggests that shame results in vulnerability to addiction to alcohol and 302 illicit drugs, but there is little understanding of the mechanisms underlying this 303 relationship. Similarly, there is an absence of evidence relating to the age at which 304 shame-prone adolescents are most vulnerable to substance use. Few studies have 305 investigated young people exclusively, and, of the papers reviewed here, none has 306 compared adolescents at different developmental stages. It may be that there is a 307 point of 'greatest vulnerability' and, if so, there will be significant implications for the 308 ways in which adolescents are educated about alcohol and illicit substances, and 309 preventative measures are established. In addition, the majority of the studies used 310 samples in which females were over-represented. Future work should attempt to 311 redress the balance by investigating the shame-substance use relationship in young 312 people of both sexes.

313 In this review, only papers relating to Western cultures were included. Although 314 there was a clear rationale for this, given the prevalence of adolescent substance 315 use in the UK and USA, there has been limited scope to investigate the shame316 substance use relationship, or the meaning surrounding substance use, in social 317 sub-groups. Although some studies used samples diverse in ethnicity and age, the 318 present review has noted little that is relevant to constructs of class or religious 319 belief. Although such factors have been investigated to only a limited degree, some 320 research has attempted to improve our understanding of them (Rastogi \& Wadhwa, 321 2006; Sandberg, 2010). Using substances may result in heightened shame only in 322 specific groups; alternatively, certain social clusters may be more or less inclined 323 toward substance use. It should not be presumed that the findings of this review can 324 be applied to all groups without further exploration of salient factors. 


\section{Conclusions and future directions}

326 The papers reviewed here indicate that adverse early experiences are associated

327 with the development of shame, that behaviours considered to be impulsive and

328 maladaptive, such as substance use, are significantly associated with feeling

329 shameful (Abramowitz \& Berenbaum, 2007; Dearing et al., 2005; Edwall et al.,

330 1989), and that amongst college students alcohol use arises from a desire to avoid

331 unwanted feelings of isolation and inadequacy (Lashbrook, 2000). The absence of

332 literature relating to shame and substance use indicates a significant gap in

333 theoretical understanding. Nevertheless, a recent bio psychosocial theory of

334 motivation postulates that behaviour is fundamentally unstable and constantly re-

335 determined on the basis of myriad stimuli, impulses and inhibitory forces (West \&

336 Brown, 2013). Consequently, vulnerability to engaging in substance use is unlikely

337 to be constant; rather, individuals may present with heightened or diminished

338 vulnerability at specific time-points, contingent on a number of predisposing and

339 precipitating factors, such as the factors related to self-concept suggested here

340 (West \& Brown, 2013). Recent findings from longitudinal research have concluded

341 that, whereas guilt-proneness in childhood predicts reduced substance use in alter

342 adolescence, proneness to shame results in heightened engagement in risky

343 behaviours, including use of alcohol and other drugs, independent of the influence of

344 socioeconomic status (Stuewig et al., 2014). The results indicate that children's

345 moral and emotional styles appear to be established even in middle childhood, and

346 that there are clear and significant implications for behaviours which commonly

347 occur in early adulthood. Further research should seek to investigate the

348 mechanisms underlying these relationships and to ascertain the point at which

349 appropriate interventions should be provided. 
351 Abramowitz, A., \& Berenbaum, H. (2007). Emotional triggers and their relation to impulsive and compulsive psychopathology. Personality and Individual

Cook, D. R. (1987). Measuring shame: The Internalized Shame Scale. Alcoholism Treatment Quarterly, 4(2), 197-215.

Allen, J. P., \& Land, D. (1999). Attachment in adolescence. In J. Cassidy \& P. R. Shaver (Eds.), Handbook of attachment: Theory, research, and clinical applications (pp. 319-335). London: Guildford.

Arentzen, W. P. (1978). Impact of alcohol misuse on family-life. Alcoholism-Clinical and Experimental Research, 2(4), 349-351.

Arnett, J. (1995). The young and the reckless: Adolescent reckless behavior. Current Directions in Psychological Science, 4(3), 67-71.

Bauman, A., \& Phongsavan, P. (1999). Epidemiology of substance use in adolescence: Prevalence, trends and policy implications. Drug and Alcohol Dependence, 55(3), 187-207.

Blume, S. B. (1990). Chemical dependency in women: Important issues. American Journal of Drug and Alcohol Abuse, 16(3-4), 297-307.

Bradshaw, J. (2005). Healing the shame that binds you. Deerfield Beach, FL: $\mathrm{HCl}$.

Clark, A. (2012). Working with guilt and shame. Advances in Psychiatric Treatment, $18(2), 137-143$.

contamination: The impact of mental illness and drug dependence stigma on family members. Journal of Family Psychology, 20(2), 239-246. 
377 Dearing, R. L., Stuewig, J., \& Tangney, J. P. (2005). On the importance of

378

379

380

381

382

383

384

385

386

387

388

389

390

391

392

393

394

395

396

397

398

399

400

401

402

distinguishing shame from guilt: Relations to problematic alcohol and drug use. Addictive Behaviors, 30(7), 1392-1404.

Dielman, T. E., Campanelli, P. C., Shope, J. T., \& Butchart, A. T. (1987). Susceptibility to peer pressure, self-esteem, and health locus of control as correlates of adolescent substance abuse. Health Education \& Behavior, 14(2), 207-221.

Edwall, G. E., Hoffmann, N. G., \& Harrison, P. A. (1989). Psychological correlates of sexual abuse in adolescent girls in chemical dependency treatment. Adolescence, 24(94), 279-288.

Feiring, C., Deblinger, E., Hoch-Espada, A., \& Haworth, T. (2002). Romantic relationship aggression and attitudes in high school students: The role of gender, grade, and attachment and emotional styles. Journal of Youth and Adolescence, 31(5), 373-385.

Fossum, M. A., \& Mason, M. J. (1986). Facing shame: Families in recovery. New York: W.W. Norton.

Gilbert, P. (2002). Body shame: A biopsychosocial conceptualization and overview with treatment implications. In P. Gilbert \& J. Miles (Eds.), Body shame: Conceptualization, research \& treatment (pp. 3-54). Hove, UK: BrunnerRoutledge.

Gross, C. A., \& Hansen, N. E. (2000). Clarifying the experience of shame: The role of attachment style, gender, and investment in relatedness. Personality and Individual Differences, 28(5), 897-907.

Gunzerath, L., Hewitt, B. G., Li, T. K., \& Warren, K. R. (2011). Alcohol research: Past, present, and future. Annals of the New York Academy of Sciences, 1216, 1-23.

Hayaki, J., Friedman, M. A., \& Brownell, K. D. (2002). Shame and severity of bulimic symptoms. Eating Behaviors, 3, 73-83. 
403 Institute for Alcohol Studies. (2013). Children, adolescents and underage drinking. 404 London: IAS. Retrieved from

405 http://www.ias.org.uk/uploads/pdf/Factsheets/Underage\%20drinking $406 \quad$ \%20factsheet\%20December\%202013.pdf

407 Jeffrey, T. B., \& Jeffrey, L. K. (1991). Psychologic aspects of sexual abuse in 408 adolescence. Current Opinion in Obstetrics \& Gynecology, 3(6), 825-831.

409 Koepke, S., \& Denissen, J. J. A. (2012). Dynamics of identity development and 410 separation-individuation in parent-child relationships during adolescence and 411 emerging adulthood - A conceptual integration. Developmental Review, 32(1),

413 Kugler, K., \& Jones, W. H. (1992). On conceptualizing and assessing guilt. Journal of 414 Personality and Social Psychology, 62(2), 318-327.

Lashbrook, J. T. (2000). Fitting in: Exploring the emotional dimension of adolescent peer pressure. Adolescence, 35(140), 747-757.

Lewis, M. (1995). Shame: The exposed self. New York: Simon \& Schuster.

418 Lewis, M. (2003). The role of the self in shame. Social Research, 70(4), 1181-1204.

419 Lewis, M. D. (2008). Self-conscious emotions: Pride, shame and guilt. In J. M.

420 Haviland-Jones, P. L. F. Barrett, \& M. D. Lewis (Eds.), Handbook of emotions

421 (3rd ed., pp. 742-757). Guilford Press.

422 Luoma, J. B., Twohig, M. P., Waltz, T., Hayes, S. C., Roget, N., Padilla, M., \& Fisher, G. 423 (2007). An investigation of stigma in individuals receiving treatment for substance abuse. Addictive Behaviors, 32(7), 1331-1346.

Martin, C. S., Chung, T., \& Langenbucher, J. W. (2008). How should we revise diagnostic criteria for substance use disorders in the DSM-V? Journal of Abnormal Psychology, 117(3), 561-575. and addiction (pp. 175-194). New York: The Howarth Press. 
430 Moretti, M. M., \& Tory-Higgins, E. (1990). Relating self-discrepancy to self-esteem:

431 The contribution of discrepancy beyond actual-self ratings. Journal of

432 Experimental Social Psychology, 26(2), 108-123.

433

Nathanson, D. (1987). The shame/pride axis. In H. B. Lewis (Ed.), The role of shame in symptom formation. Hillsdale, New Jersey: Lawrence Erlbaum Associates.

NHSIC. (2011). Statistics on drug misuse: England. The Health and Social Care Information Centre.

O'Connor, L. E., Berry, J. W., Inaba, D., \& Weiss, J. (1994). Shame, guilt, and depression in men and women in recovery from addiction. Journal of Substance Abuse Treatment, 11(6), 503-510.

Peñas-Lledó, E., Fernández, J. de D., \& Waller, G. (2004). Association of anger with bulimic and other impulsive behaviours among non-clinical women and men. European Eating Disorders Review, 12(6), 392-397.

Potter-Efron, R. (1987). Shame and guilt: Definitions, processes and treatment issues with AODA clients. Alcoholism Treatment Quarterly, 4(2), 7-24.

Pulakos, J. (1996). Family environment and shame: Is there a relationship? Journal of Clinical Psychology, 52(6), 617-623.

447 Quiles, Z. N., Kinnunen, T., \& Bybee, J. (2002). Aspects of guilt and self-reported 448 substance use in adolescence. Journal of Drug Education, 32(4), 343-362.

Rastogi, M., \& Wadhwa, S. (2006). Substance abuse among Asian Indians in the United States: A consideration of cultural factors in etiology and treatment. Substance Use \& Misuse, 41(9), 1239-1249.

Reed, B. G. (1987). Developing women-sensitive drug dependence treatment services: Why so difficult? Journal of Psychoactive Drugs, 19(2), 151-164. shame in adolescence. Developmental Review, 16, 321-363. 
456 Rosenkranz, S. E., Henderson, J. L., Muller, R. T., \& Goodman, I. R. (2012). Motivation and maltreatment history among youth entering substance abuse treatment. Psychology of Addictive Behaviors, 26(1), 171-177.

Sandberg, S. (2010). "The sweet taste of sin"-A Muslim drug dealer in a Nordic welfare state. Journal of Scandinavian Studies in Criminology and Crime Prevention, 11(2), 103-118.

Stuewig, J., \& McCloskey, L. A. (2005). The relation of child maltreatment to shame and guilt among adolescents: Psychological routes to depression and delinquency. Child Maltreatment, 10(4), 324-336.

Stuewig, J., Tangney, J. P., Kendall, S., Folk, J. B., Meyer, C. R., \& Dearing, R. L. (2014). Children's proneness to shame and guilt predict risky and illegal behaviors in young adulthood. Child Psychiatry \& Human Development, 1-11.

Talbot, J. A., Talbot, N. L., \& Tu, X. (2004). Shame-proneness as a diathesis for dissociation in women with histories of childhood sexual abuse. Journal of Traumatic Stress, 17(5), 445-448.

Tangney, J. P. (1990). Assessing individual differences in proneness to shame and guilt: Development of the Self-Conscious Affect and Attribution Inventory. Journal of Personality and Social Psychology, 59(1), 102-111.

477 Wicker, F. W., Payne, G. C., \& Morgan, R. D. (1983). Participant descriptions of guilt 478 and shame. Motivation and Emotion, 7, 25-39. maltreatment and later psychological distress among college students: The mediating role of maladaptive schemas. Child Abuse \& Neglect, 33(1), 59-68. 
482 Zahn-Waxler, C., Radke-Yarrow, M., Wagner, E., \& Chapman, M. (1992). Development 483 of concern for others. Developmental Psychology, 28(1), 126-136. 


\section{Table $\mathbf{1}$ (on next page)}

Table 1 
200 Emotional triggers as a predictor of impulsive-

compulsive behaviours

Abramowitz, A., \& Berenbaum, H. Emotional triggers and their relation to impulsive and compulsive

psychopathology.

Dearing, R. L., Stuewig, J., \& Tangney, J. P. On the importance of distinguishing shame from guilt: Relations

to problematic alcohol and drug use.

Edwall, G. E., Hoffmann, N. G., \& Harrison, P. A

Psychological correlates of sexual abuse in adolescent girls in chemical dependency treatment.

Lashbrook, J. T. Fitting in: Exploring the emotional dimension of adolescent peer pressure.

\section{BIS-11, OCl College}

Students
200 Clarifying the role of shame 5 and guilt in substance use

198 Psychopathology \& selfconcept in victims of sexual use

200 Emotions and conformity
Students \& inmates

Adolescent females counsellors females
597 Sexual abuse \& shame are common in substance use
Correlational study

predict I-C
Limited data abuse re: severity of

\section{Correlation} with substance use in both samples

data

College
students
Facets of shame

motivate individuals to drink alcohol with peers 
Quiles, Z. N., Kinnunen, T., \& Bybee, J. Aspects of quilt and self-reported substance use in adolescence.

Rosenkranz, S. E., Henderson, J. L., Muller, R. T., \&

Goodman, I. R. Motivation and maltreatment history among youth entering substance abuse treatment.
200 The relationship between

guilt and adolescent

substance use

TOSCA, GI,

MFCGI, PFQ2

Students

230
have weaker
internalisation of

Substance users

societal standards

Retrospective

self-report

data

Focus on guilt

201 The relationship between

maltreatment and motivation

to change

SOCRATES,

TEQ, TAQ,

AUDIT, DAST,

$16-24$

year-old

substance

188

Shames is

associated with

substance use

$89 \%$ positive

response rate

Self-reported

maltreatment 
PeerJ Reviewing Manuscript 